\title{
Hypocretin/Orexin Selectively Increases Dopamine Efflux within the Prefrontal Cortex: Involvement of the Ventral Tegmental Area
}

\author{
Nicole M Vittoz' and Craig W Berridge*,' \\ 'Department of Psychology, University of Wisconsin, Madison, WI, USA
}

\begin{abstract}
Hypocretins (HCRTs) modulate a variety of behavioral and physiological processes, in part via interactions with multiple ascending modulatory systems. Further, HCRT efferents from the lateral hypothalamus innervate midbrain dopamine (DA) nuclei, and DA cell bodies express HCRT receptors. Combined, these observations suggest that HCRT may influence behavioral state and/or statedependent processes via modulation of DA neurotransmission. The current studies used in vivo microdialysis in the unanesthetized rat to first characterize the effect of intracerebroventricular infusion of HCRT-I $(0.07,0.7 \mathrm{nmol})$ on extracellular levels of DA within the prefrontal cortex (PFC) and nucleus accumbens (Acc). Electroencephalographic/electromyographic measures of sleep-wake state were collected along with select behavioral measures (eg locomotor activity, grooming). HCRT-I dose-dependently increased PFC dialysate DA levels, and these increases were closely correlated with increases in time spent awake. In contrast, Acc DA levels were unaffected. Additional studies examined whether HCRT-I acts directly within the ventral tegmental area (VTA) to selectively increase PFC DA efflux and modulate behavioral state. Unilateral infusion of HCRT-I $(0.1,1.0 \mathrm{nmol})$ within the VTA increased PFC, but not Acc, DA levels. Importantly, intra-VTA infusion of HCRT-I increased the time spent awake and grooming. Moreover, HCRT-induced increases in both time spent awake and time spent grooming were significantly correlated with post-infusion PFC DA levels. The current observations predict a prominent modulatory influence of HCRT on PFC-dependent cognitive and affective processes that results, in part, from actions within the VTA. Additionally, these observations suggest that the activation of VTA DA neurons contributes to the behavioral state-modulatory actions of HCRT.
\end{abstract}

Neuropsychopharmacology (2006) 3I, 384-395. doi:I0.1038/sj.npp. I 300807; published online 29 June 2005

Keywords: hypocretin; orexin; dopamine; prefrontal cortex; ventral tegmental area; arousal

\section{INTRODUCTION}

The hypocretin (HCRT) (orexin) peptide family consists of two peptides (HCRT-1, HCRT-2) synthesized within the perifornical region of the lateral hypothalamus (de Lecea et al, 1998; Sakurai et al, 1998). These peptides have been implicated in the regulation of behavioral state and statedependent processes. For example, central administration of HCRT-1 exerts potent wake-promoting actions (Piper et al, 2000; España et al, 2001). Moreover, dysregulated HCRT neurotransmission is associated with the sleep/ arousal disorder narcolepsy (for reviews, see Hungs and Mignot, 2001; Scammell, 2001). In addition, central HCRT administration increases indices of both stressful and appetitive states, suggesting that HCRT may also participate

*Correspondence: Dr CW Berridge, Department of Psychology, University of Wisconsin, 1202 W. Johnson St., Madison, WI 53706, USA, Tel: + | 608265 5938, Fax: + | 608262 4029,

E-mail: berridge@wisc.edu

Received 25 March 2005; revised and accepted 16 May 2005

Online publication: 25 May 2005 at http://www.acnp.org/citations/ Npp052505050203/default.pdf in physiological and behavioral processes associated with high-arousal environmental conditions (Sakurai et al, 1998; Ida et al, 2000; Jaszberenyi et al, 2000; Samson et al, 2002; España et al, 2003). Combined, these observations suggest a pivotal role for the HCRT system in the regulation of behavioral state and state-dependent processes associated with alert, active waking.

Dopaminergic systems also modulate behavioral state and state-dependent processes, particularly under high-arousal appetitive and aversive conditions (Trulson, 1985; Smith et al, 1992; Arnsten et al, 1994; Isaac and Berridge, 2003). Acting within the prefrontal cortex (PFC) and nucleus accumbens (Acc), dopamine (DA) exerts prominent modulatory actions on a variety of higher-level cognitive and affective processes (Ikemoto and Panksepp, 1999; SmithRoe and Kelley, 2000; Baldwin et al, 2002). Thus, it is of interest that HCRT fibers are found in close association with DA neurons located within the ventral tegmental area (VTA) and substantia nigra (Peyron et al, 1998; Fadel and Deutch, 2002; Baldo et al, 2003). Further, VTA and substantia nigra neurons express HCRT1 and HCRT2 receptor mRNA (Marcus et al, 2001). Finally, in vitro, 
HCRT-1 activates VTA (though not substantia nigra) DA neurons (Uramura et al, 2001; Korotkova et al, 2002, 2003). Combined, these observations suggest that HCRT modulates DA neurotransmission and that this action may contribute to HCRT-induced alterations in behavioral state and state-dependent processes.

A critical question unaddressed in the previous studies is the extent to which HCRT impacts DA neurotransmission in the intact animal. Dopaminergic neurons within the VTA project to a variety of terminal fields, including the PFC, Acc and striatum. Importantly, these various terminal fields display differential sensitivity to environmental and pharmacological manipulations. In particular, DA terminals within the PFC display the greatest sensitivity to both appetitive and aversive (eg stress) conditions (Thierry et al, 1976; Dunn, 1988; Roth et al, 1988; Cenci et al, 1992). Under similar conditions, Acc DA terminals typically display reduced, and striatal terminals minimal, reactivity (Dunn, 1988; Abercrombie et al, 1989; Cenci et al, 1992). Each of these regions support a variety of distinct cognitive and affective processes. Thus, it is essential to delineate the actions of this peptide on DA neurotransmission across distinct forebrain terminal fields.

Toward this goal, the current studies first sought to characterize the degree to which intracerebroventricular (ICV)-administered HCRT-1 activates DA neurotransmission across various terminal fields utilizing in vivo microdialysis in the unanesthetized rat. Electroencephalographic (EEG) and electromyographic (EMG) measures of sleep-wake state as well as behavioral measures of locomotion and grooming were collected to preliminarily assess the degree to which HCRT-induced activation of DA neurotransmission might contribute to the behavioral actions of this peptide. In these studies, ICV HCRT-1 dose-dependently increased extracellular DA levels within the PFC. Interestingly, Acc DA levels were unaffected by HCRT-1 administration. The VTA is a major source of DA fibers projecting to both PFC and Acc. Additional studies were conducted to better determine the degree to which the selective increase in DA efflux within the PFC involves actions of HCRT-1 directly within the VTA. In these studies, HCRT-1 was infused directly into VTA and DA efflux measured within the PFC and Acc.

\section{MATERIALS AND METHODS}

\section{Animals and Surgery}

Male Sprague-Dawley rats weighing 260-280g (Charles River, Wilmington, MA) were housed in groups of $2-3$ on a 13/11-h light/dark cycle (lights on at $0600 \mathrm{~h}$ ) and provided ad lib access to food and water for 1-3 weeks following arrival. At 1-2 days prior to testing, a microdialysis probe (see below) was lowered unilaterally either into PFC $(+3.2$ $\mathrm{A} / \mathrm{P} ; \pm 1.0 \mathrm{M} / \mathrm{L} ;-5.0 \mathrm{D} / \mathrm{V}$ at an angle of $4^{\circ}$ from vertical) or into Acc $(+1.7 \mathrm{~A} / \mathrm{P} ; \pm 1.4 \mathrm{M} / \mathrm{L} ;-7.9 \mathrm{D} / \mathrm{V})$ under halothane anesthesia. All coordinates are referenced to Bregma with level skull. Probes were inserted at a rate of approximately $500 \mu \mathrm{m} / \mathrm{min}$ to minimize tissue damage and ensure adequate levels of DA within the cortical dialysate. In animals with PFC microdialysis probes, a bipolar EEG electrode was implanted into the contralateral frontal cortex
$(+3.0 \mathrm{~A} / \mathrm{P} ; \pm 1.5 \mathrm{M} / \mathrm{L})$ and a bipolar EMG electrode was implanted into the dorsal neck muscle (see below). A ground screw was implanted over the cerebellum. The free ends of the EEG, EMG and ground wires were threaded into a plastic connector. A guide cannula (Plastics One, Roanoke, VA) was implanted unilaterally, aimed at either the lateral ventricle contralateral to the dialysis probe $(-1.0$ $\mathrm{A} / \mathrm{P} ; \pm 1.35 \mathrm{M} / \mathrm{L} ;-1.4 \mathrm{D} / \mathrm{V})$ or the VTA $(-5.4 \mathrm{~A} / \mathrm{P} ; \pm 1.6 \mathrm{M} /$ $\mathrm{L} ;-3.8 \mathrm{D} / \mathrm{V}$ at an angle of $5^{\circ}$ from vertical) ipsilateral to the probe. For ICV studies, a 26-gauge cannula and 33-gauge infusion needle were used. For intra-VTA studies, a 23gauge cannula and 30-gauge infusion needle were used, due to a tendency for needle clogging at higher peptide concentrations. Probe placement was counterbalanced across the left and right hemispheres. The connector, cannula, and dialysis probe were cemented into position using acrylic cement (Plastics One). A stainless steel wire stylet was inserted and attached to the cannula using a threaded plastic connector (Plastics One). Following probe implantation, animals were transferred to the testing chamber (see below) and artificial extracellular fluid (AECF) was perfused through the dialysis probe overnight at a flow rate of $1.5 \mu \mathrm{l} / \mathrm{min}$. All surgical and experimental procedures were performed in accordance with University of Wisconsin Institutional Animal Care and Use Committee guidelines, and the National Institutes of Health (1996) Guide for the Care and Use of Laboratory Animals.

\section{Experimental Procedures}

Following probe implant, animals were placed in a Plexiglas testing chamber $\left(32 \times 32 \times 40 \mathrm{~cm}^{3}\right)$ overnight. Each Plexiglas testing chamber was housed in a wooden, soundattenuating outer chamber containing a $15 \mathrm{~W}$ light bulb, a speaker through which white noise $(60 \mathrm{~dB})$ was played, and a $12 \mathrm{~V}$ fan running at reduced speed. A $10-\mathrm{cm}$ hole in the top panel of the outer chamber permitted entry of EEG cables. A second hole in the front panel of the outer chamber permitted videotaping of the animal.

On the morning of testing, between 0900 and $1000 \mathrm{~h}$, an infusion needle (Plastics One) was connected to a PE20 tubing threaded through a stainless steel spring. For ICV studies, animals received a unilateral $2 \mu$ infusion of AECF, 0.07 nmol HCRT-1 or 0.7 nmol HCRT-1 (Orexin-A; Penninsula Laboratories, Merseyside, UK; dissolved in AECF). For the intra-VTA experiment, animals received a unilateral $250 \mathrm{nl}$ infusion of AECF, $0.1 \mathrm{nmol} \mathrm{HCRT-1}$ or $1.0 \mathrm{nmol}$ HCRT-1 (Orexin-A; Bachem, King of Prussia, PA; dissolved in AECF). In all cases, an air bubble (approximately $150 \mathrm{nl}$ ) was used to separate infusate from water in the PE20 tubing. The needle was then inserted into the cannula and secured with a plastic threaded sleeve, the needle tip extending $2.5 \mathrm{~mm}$ (ICV) or $4 \mathrm{~mm}$ (intra-VTA) beyond the end of the cannula. Infusions were made using a microprocessorcontrolled pump (Harvard Apparatus, South Natick, MA) at a rate of $1 \mu \mathrm{l} / \mathrm{min}$ (ICV) or $150 \mathrm{nl} / \mathrm{min}$ (intra-VTA). At least four 16-min dialysis samples were collected prior to infusion. Infusions were typically made following at least two consecutive samples in which the majority of the time was spent asleep. Collection of the first post-infusion sample began just prior to the infusion. Sample collection continued for at least eight samples following infusion or 
until DA levels had returned to baseline, generally between 1500 and 1600. For purposes of statistical analyses, DA values were calculated as a percent of baseline. The baseline value was determined by averaging three pre-infusion samples from epochs in which the animal spent the majority of time asleep.

\section{Microdialysis and High-Pressured Liquid Chromatography (HPLC) Analysis of DA Concentrations}

DA was measured in dialysate samples using HPLC with electrochemical detection, as described previously (Berridge and Stalnaker, 2002). Briefly, AECF (147 mM NaCl, $1.3 \mathrm{mM}$ $\mathrm{CaCl}_{2}, 0.9 \mathrm{mM} \mathrm{MgCl}, 2.5 \mathrm{mM} \mathrm{KCl} ; \mathrm{pH} 7.4$ ) was delivered at a rate of $1.5 \mu \mathrm{l} / \mathrm{min}$ through PE10 tubing to a length of Spectra/Por hollow fiber (Spectrum Labs, Rancho Dominguez, CA; MW cutoff 13000 ; o.d. $250 \mu \mathrm{m}$ ) or modified cellulose membrane (Gambro, Lakewood, CO; MW cutoff 6000 ; o.d. $250 \mu \mathrm{m}$ ). The dialysis membrane was sealed and attached to the PE10 tubing with 5-min epoxy. The length of functional dialysis membrane in contact with tissue was $4 \mathrm{~mm}$ for PFC and $2 \mathrm{~mm}$ for Acc. A $75 \mathrm{~cm}$ length of fused silica $(150 \mu \mathrm{m}$ o.d., $75 \mu \mathrm{m}$ i.d.) provided outflow to a sample collection vial outside the sound-attenuating chamber. In vitro recovery tests were performed prior to implantation; only probes with recovery $>10 \%$ were used.

Dialysis samples were collected at intervals of approximately $16 \mathrm{~min}$ prior to and following vehicle or HCRT administration. Samples of $20 \mu \mathrm{l}$ were injected onto an HPLC-EC system consisting of an ESA Model 582 pump set at $0.65 \mathrm{ml} / \mathrm{min}$, a Velosep C18 $100 \times 3.2 \mathrm{~mm}$ cartridge, and an ESA 5100A Coulochem II detector with two electrodes in series: $-0.025 \mathrm{~V},+0.220 \mathrm{~V}$. The mobile phase consisted of $200 \mathrm{mM}$ sodium phosphate (pH 3.0-5.2), $0.1 \mathrm{mM}$ EDTA, $0.3 \mathrm{mM}$ sodium octyl-sulfate, and $5 \% \mathrm{v} / \mathrm{v}$ methanol. The quantitation limit for DA was approximately $0.2 \mathrm{pg}$ (approx. $3 \times$ noise). The mean amount of DA recovered per $20 \mu \mathrm{l}$ baseline sample (low-arousal) was $1.04 \pm 0.05 \mathrm{pg}(n=35)$ within the PFC and $9.52 \pm 1.58 \mathrm{pg}(n=1 \overline{1})$ within the Acc (see Figure 1 for sample PFC chromatogram).

\section{EEG/EMG and Behavior Analyses}

In the subset of animals with PFC probes (both ICV- and intra-VTA-treated animals), a bipolar surface-to-depth EEG electrode was inserted into the contralateral frontal cortex, as described previously (Berridge and Foote, 1996). EMG was recorded using two $4 \mathrm{~cm}$ lengths of flexible, insulated wire (Cooner Wire, Chatsworth, CA) threaded into the dorsal neck muscle and positioned such that an approximately $3 \mathrm{~mm}$ portion of exposed wire was in direct contact with tissue. EEG and EMG signals were amplified and filtered $(1.0-100.0 \mathrm{~Hz}, \mathrm{EEG} ; 1.0-30.0 \mathrm{~Hz}, \mathrm{EMG})$ and recorded on a chart recorder and VCR recording tape.

EEG and EMG were scored for the following behavioral state categories: (1) slow-wave sleep (high-voltage EEG, lowvoltage EMG); (2) REM sleep (low-voltage EEG combined with EMG activity approximately 50\% lower amplitude than that observed in slow-wave sleep, with occasional short-duration, large-amplitude deflections due to muscle twitches); (3) quiet waking (low-voltage EEG with EMG activity of an average amplitude twice that observed in slowwave sleep); (4) active waking (low-voltage EEG, sustained high-voltage EMG of approximately twice that observed in quiet waking, with frequent movement deflections). To be scored as a distinct epoch, the appropriate cortical EEG and EMG activity patterns needed to persist for a minimum of $15 \mathrm{~s}$. Time spent in each state was scored and totaled for each 16-min dialysis sample collection period by an observer blind to experimental conditions.

Behavioral analyses were also performed on the subset of animals with PFC probes. In these analyses, the frequency of quadrant entries and rears as well as time spent grooming were scored from a videotape, using a computer-based event recorder (Noldus Information, Wageningen, Netherlands). Behavioral analyses were conducted for the 30-min epoch immediately preceding infusion and the first three 30-min post-infusion epochs by an observer blind to experimental conditions.

\section{Histological Analyses and Data Selection}

After testing, animals were deeply anesthetized with halothane and transcardially perfused with $60 \mathrm{ml}$ of $4 \%$ formaldehyde. In the ICV study, animals received $2 \mu \mathrm{ICV}$ of $0.5 \%$ Chicago Blue dye approximately $5 \mathrm{~min}$ prior to perfusion. Placement of microdialysis probes were histologically verified in $50-\mu \mathrm{m}$-thick coronal sections stained with Neutral Red dye. Infusion needle placement was verified by histological examination and, in the ICV study, by observing dye distribution. Data were included only when (1) histological analyses verified accurate placement of needles and microdialysis probes, and (2) DA concentrations during sleeping baseline epochs were stable $( \pm 10 \%)$.

\section{Statistical Analyses}

PFC DA (percent baseline) and EEG/EMG data were analyzed using a split-design two-way ANOVA for treatment (between-subjects, three levels) and time (withinsubjects, 10 levels). Where between-subjects omnibus tests proved significant, pairwise post hoc group comparisons for each time point (sample number) were made using Fischer's LSD test. For Acc DA levels (percent baseline), animals only received the highest dose of HCRT-1. For these cases, DA data were analyzed using a one-way ANOVA, with time as a within-subjects variable (10 levels). Additional analyses for both dialysis and behavioral data utilized planned withingroup matched-pair $t$-tests between the last baseline sample and each post-infusion sample. Best-fit regressions between post-infusion levels of waking or behaviors and PFC DA levels were also performed.

\section{RESULTS}

\section{Experiment 1: ICV HCRT-1}

Effects of ICV HCRT-1 administration on PFC and Acc $D A$ levels. To characterize the effects of HCRT-1 on extracellular levels of DA within the PFC, dialysis samples were collected from the medial PFC (Figures 1 and 2a) prior to and after ICV infusions of either vehicle $(n=6)$ or HCRT-1 $(0.07 \mathrm{nmol}, n=6 ; 0.7 \mathrm{nmol}, n=6)$. These doses 


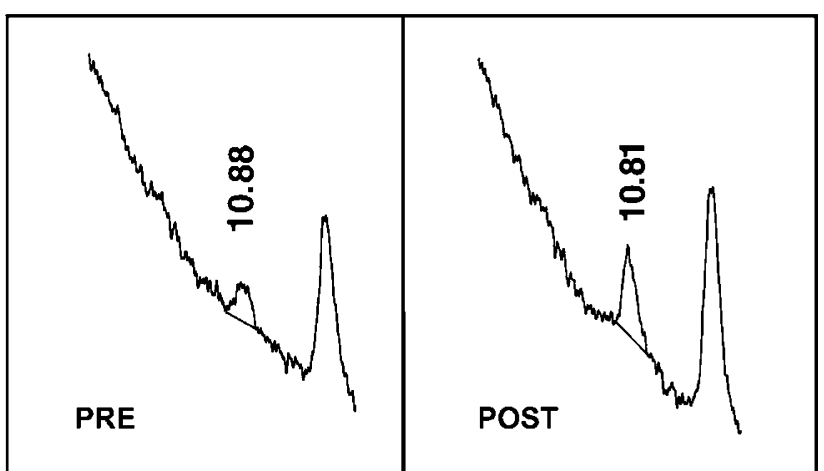

Figure I Representative chromatogram showing PFC DA levels prior to (PRE) and after (POST) ICV HCRT-I infusion ( $0.7 \mathrm{nmol})$. Numbers denote retention times for the DA peak. It is apparent that HCRT-I increased the height of the DA peak.
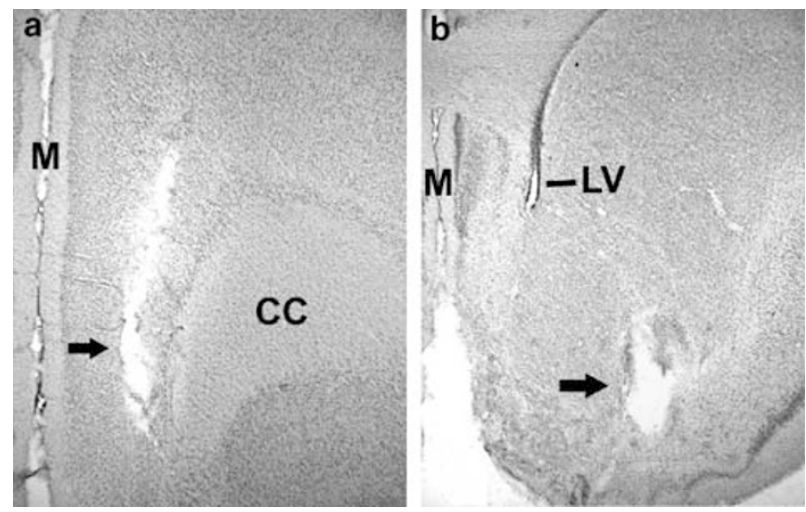

Figure 2 Photomicrographs depicting placement of dialysis probes within PFC (a) and Acc (b). For PFC, probes were placed within the medial subdivision of this region. For Acc, probes were placed, in general, in the central portion corresponding to the core subdivision. Coronal sections $(50 \mu \mathrm{m})$ were stained with Neutral Red. Arrow indicates probe track. $M=$ midline; $C C=$ corpus collosum; $A C=$ anterior commisure; $L V=$ lateral ventricle.

were chosen based on previous studies demonstrating the dose-dependent wake-promoting actions of ICV HCRT-1 across this dose range (España et al, 2001). HCRT-1 dose-dependently increased DA levels in PFC dialysate samples (treatment $\mathrm{F}_{2,15}=11.90, P<0.001$; time $\mathrm{F}_{9,135}=$ 16.53, $P<0.001$; treatment $\times$ time interaction $\mathrm{F}_{18,135}=3.07$, $P<0.001$ ). Maximal increases of 64 and $87 \%$ above baseline were observed within the second post-infusion sample following low- and high-dose HCRT-1, respectively (Figure $3 a$ and $b$ ). For both doses, PFC DA efflux remained elevated for approximately $60 \mathrm{~min}$ after infusion. Vehicle infusions did not alter PFC DA levels.

Additional studies examined the effects of the highest dose of ICV-administered HCRT-1 on extracellular DA levels in Acc ( $0.7 \mathrm{nmol}, n=6$; Figure $2 \mathrm{~b})$. In contrast to that observed within the PFC, there was no significant effect of this dose of HCRT-1 on Acc DA levels $\left(\mathrm{F}_{9,36}=0.40, P=0.93\right.$; Figure 3c).

Relationship between ICV HCRT-1-induced alterations in behavior and PFC DA levels. Similar to previous observations (España et al, 2001), ICV-administered HCRT-1 dose-
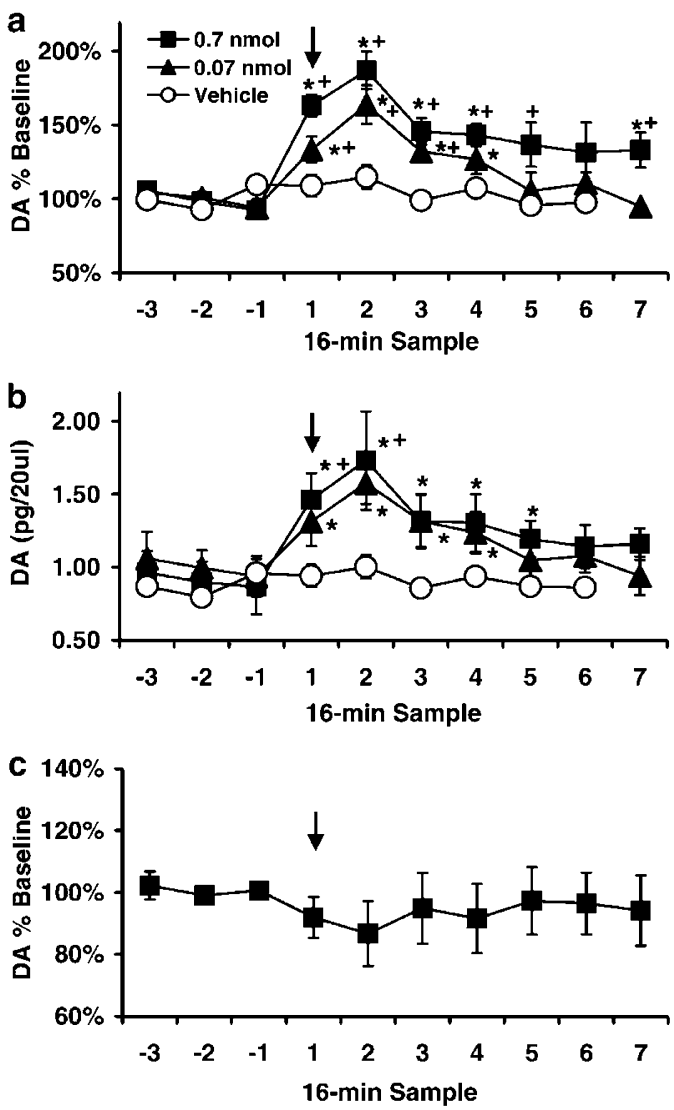

Figure 3 Effects of ICV-administered HCRT-I on PFC and Acc DA levels. Panels $a$ and $b$ depict the effects of ICV-administered vehicle, $0.07 \mathrm{nmol}$ HCRT-I, and $0.7 \mathrm{nmol}$ HCRT on DA efflux within PFC. Panel a displays mean $( \pm$ SEM) PFC DA levels as a percentage of baseline. Panel $b$ displays mean $( \pm$ SEM) PFC DA levels in $p g / 20 \mu$ l. Panel $c$ displays mean \pm SEM Acc DA levels expressed as a percentage of baseline following $0.7 \mathrm{nmol}$ HCRT-I. In all panels, data are shown for pre- (negative numbers) and post-infusion (positive numbers) 16-min samples. The start of infusion was aligned with the beginning of post-infusion Sample I (arrow). Within PFC, maximal increases in DA concentrations occurred during post-infusion Sample 2. In contrast, HCRT-I had no significant effect on Acc DA levels. $+P<0.05$ compared to vehicle; $* P<0.05$ compared to sample immediately preceding infusion (Sample -1 ).

dependently increased EEG/EMG measures of time spent awake (treatment $\mathrm{F}_{2,13}=13.13, P<0.01$; time $\mathrm{F}_{9,117}=9.76$, $P<0.001$; treatment $\times$ time $\mathrm{F}_{18,117}=4.16, P<0.001$ ). Two animals were excluded from these analyses due to inadequate EEG/EMG recordings. As previously described (España et al, 2001), the highest dose of HCRT-1 ( $0.7 \mathrm{nmol}$, $n=6)$ significantly increased the time spent awake for approximately $120 \mathrm{~min}$, while the lower dose $(0.07 \mathrm{nmol}$, $n=5$ ) elicited a shorter-duration increase in waking (data not shown). Vehicle infusion $(n=5)$ did not alter the time spent awake. Additionally, ICV-administered HCRT-1 $(0.7 \mathrm{nmol}, n=5 ; 0.07 \mathrm{nmol}, n=6$; vehicle, $n=6)$ elicited moderate increases in locomotor activity, as measured by both quadrant entries (treatment $\mathrm{F}_{2,14}=2.41, P=0.13$; time $\mathrm{F}_{3,42}=10.87, \quad P<0.001 ; \quad$ treatment $\times$ time $\quad \mathrm{F}_{6,42}=3.00$, $P<0.05$ ) and rears (treatment $F_{2,14}=14.60, P<0.001$; time $\mathrm{F}_{3,42}=10.37, P<0.001$; treatment $\times$ time $\mathrm{F}_{6,42}=7.98$, $P<0.001$ ), similar to that described previously (España 
et al, 2001). Quadrant entries and rears were significantly increased over vehicle for the low dose during the first $30 \mathrm{~min}$ post-infusion epoch (Table 1). HCRT-1 also significantly increased the time spent grooming (treatment $\mathrm{F}_{2,14}=0.83, \quad P=0.46 ;$ time $\mathrm{F}_{3,42}=4.65, P<0.01$; treatment $\times$ time interaction $\left.\mathrm{F}_{6,42}=0.80, P=0.57\right)$. Within the high-dose group, grooming increased significantly over vehicle during the third post-infusion epoch (Table 1).

Correlation analyses were conducted to better assess the degree to which HCRT-1-induced increases in DA release are associated with HCRT-1-induced alterations in sleepwake state and behavior. As shown in Figure 4a, there was a close temporal association between HCRT-1-induced increases in PFC DA levels and time spent awake. Consistent with this, best-fit regression analyses on data pooled across all groups and all post-infusion epochs (seven 16-min samples for waking; three 30-min samples for behavior) indicated a strong positive correlation between postinfusion PFC DA levels and time spent awake $(r=0.61$, $r^{2}=0.37, P<0.001$; Figure $\left.4 \mathrm{~b}\right)$. Positive correlations were also observed when data from each group were analyzed separately. Less robust correlations were observed between PFC DA levels and quadrant entries $\left(r=0.46, r^{2}=0.21\right.$,
$P<0.01)$, rears $\left(r=0.45, r^{2}=0.20, P<0.05\right)$, and grooming $\left(r=0.30, r^{2}=0.09, P<0.05\right)$.

\section{Experiment 2: Intra-VTA HCRT-1}

Effects of intra-VTA HCRT-1 administration on PFC and Acc DA levels. To assess the degree to which HCRT acts within the VTA to elicit a selective activation of DA terminals within the PFC, we examined the effects of intraVTA infusion of HCRT-1 on PFC DA levels. Animals received intra-VTA infusions (see Figures 5 and 6) of vehicle $(n=6)$ or HCRT-1 $(0.1 \mathrm{nmol}, n=5 ; 1.0 \mathrm{nmol}, n=6)$. HCRT-1 dose-dependently increased DA levels in PFC dialysate samples (treatment $\mathrm{F}_{2,14}=3.13, P=0.08$, time $\mathrm{F}_{9,126}=8.19, \quad P<0.001, \quad$ treatment $\times$ time interaction $\left.\mathrm{F}_{18,126}=1.60, P=0.07\right)$. Maximal increases of $35 \%$ above baseline were observed within the second post-infusion sample following low-dose HCRT-1, and $48 \%$ in the third sample following high-dose HCRT-1 (Figure 7a). PFC DA levels returned to baseline within approximately five samples following both doses of HCRT-1. Vehicle infusions did not significantly alter PFC DA levels, although there was a trend toward a modest increase in the second

Table I Behavioral Effects of ICV and Intra-VTA HCRT-I

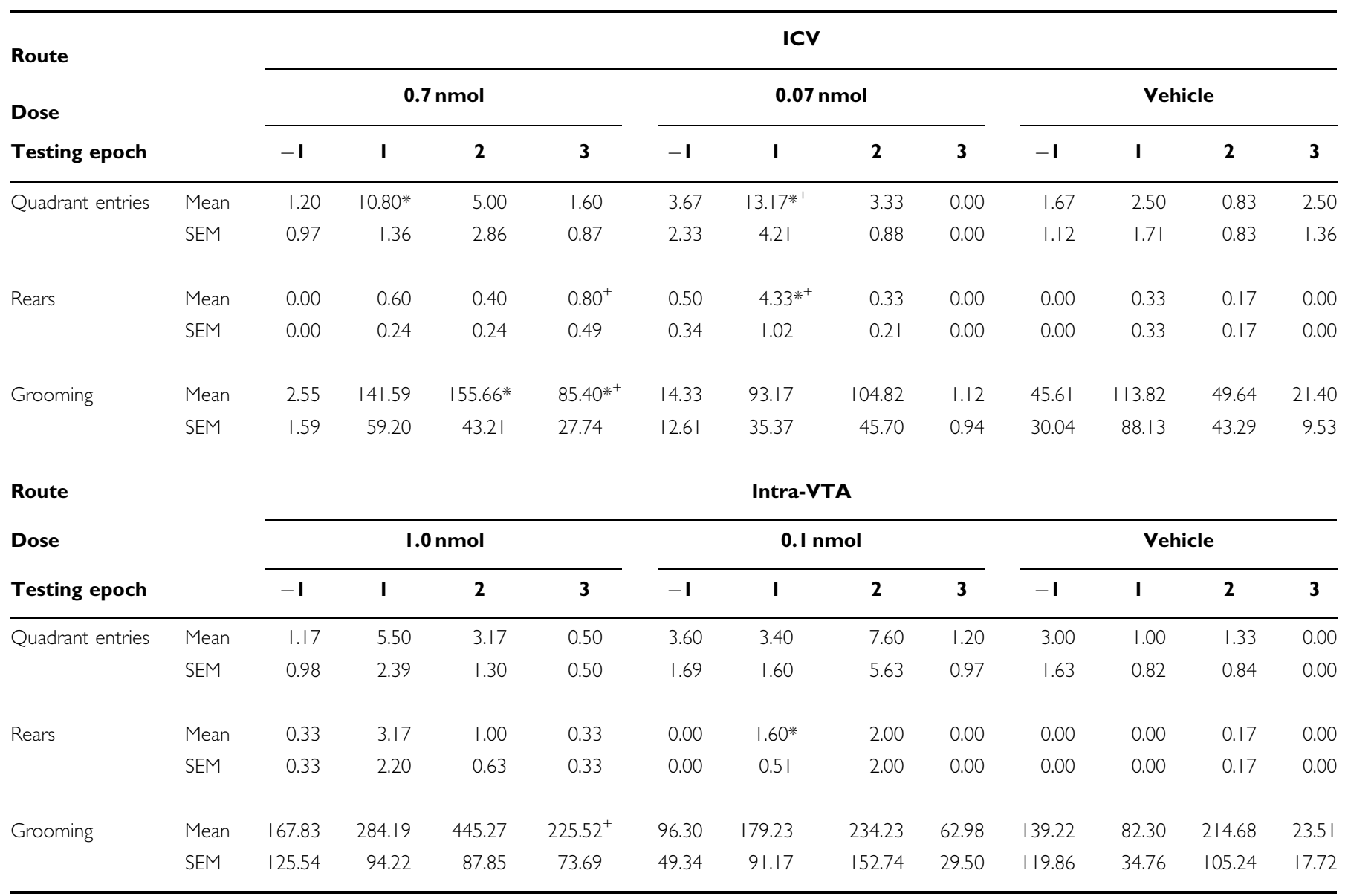

Shown are mean (and SEM) frequency of quadrant entries and rears, as well as time spent grooming (sec) across 30-min pre- $(-1)$ and post (I-3) testing epochs. ICV-administered HCRT-I significantly increased the frequency of quadrant entries and rears and time spent grooming. Intra-VTA-administered HCRT-I significantly increased rears and grooming. ${ }^{+} P<0.05$ compared to vehicle; $* P<0.05$ compared to baseline (Epoch -1$)$. 

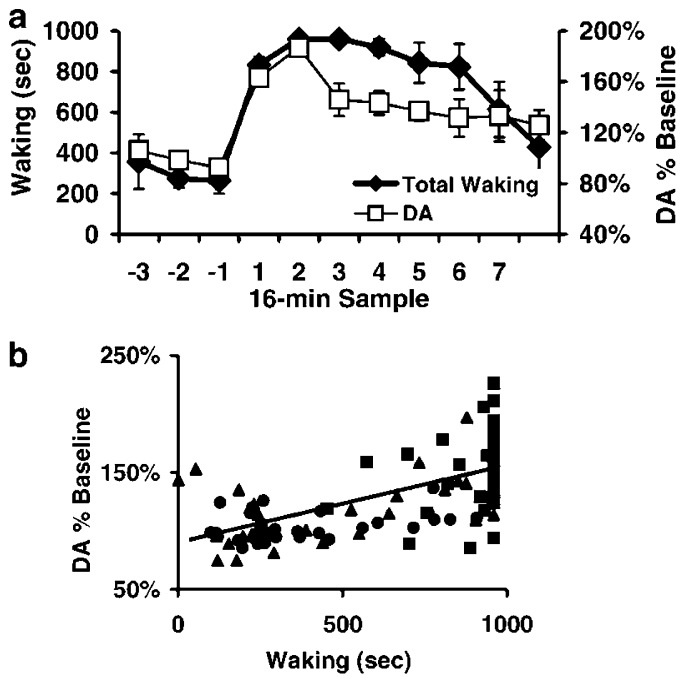

Figure 4 Relationship between ICV-administered HCRT-I-induced increases in PFC DA and waking. (a) Displayed are mean ( \pm SEM) DA levels (percent baseline) and time spent awake (sec). It is evident that there is a relatively close temporal relationship between HCRT-I-induced $(0.7 \mathrm{nmol})$ increases in DA levels and waking. (b) Scatterplot showing the best fit line between waking and DA levels over all seven post-infusion samples. Different shapes represent treatment groups: squares $(0.7 \mathrm{nmol})$; triangles $(0.07 \mathrm{nmol})$; circles (vehicle). Regression analyses indicated a strong positive correlation between PFC DA levels and time spent awake after ICV infusion of HCRT-I (best-fit regression $r=0.6 \mathrm{I}, r^{2}=0.37$ ). During initial post-infusion samples, HCRT-I elicited sustained waking throughout the sample epoch.

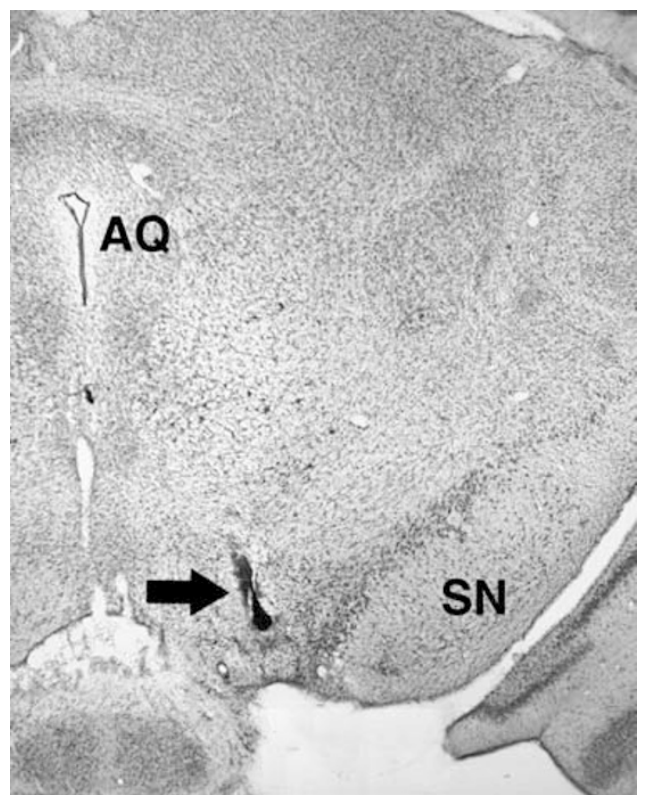

Figure 5 Photomicrograph depicting infusion needle placement within VTA. Coronal sections $(50 \mu \mathrm{m})$ were stained with Neutral Red. Arrow indicates the most ventral extent of the infusion needle; $A Q=$ cerebral aqueduct, $\mathrm{SN}=$ substantia nigra.

post-infusion sample. Although a full mapping study was not carried out, infusions placed dorsal to VTA, within the extreme medial region of VTA or within the medial substantia nigra, had no significant effect on PFC DA levels
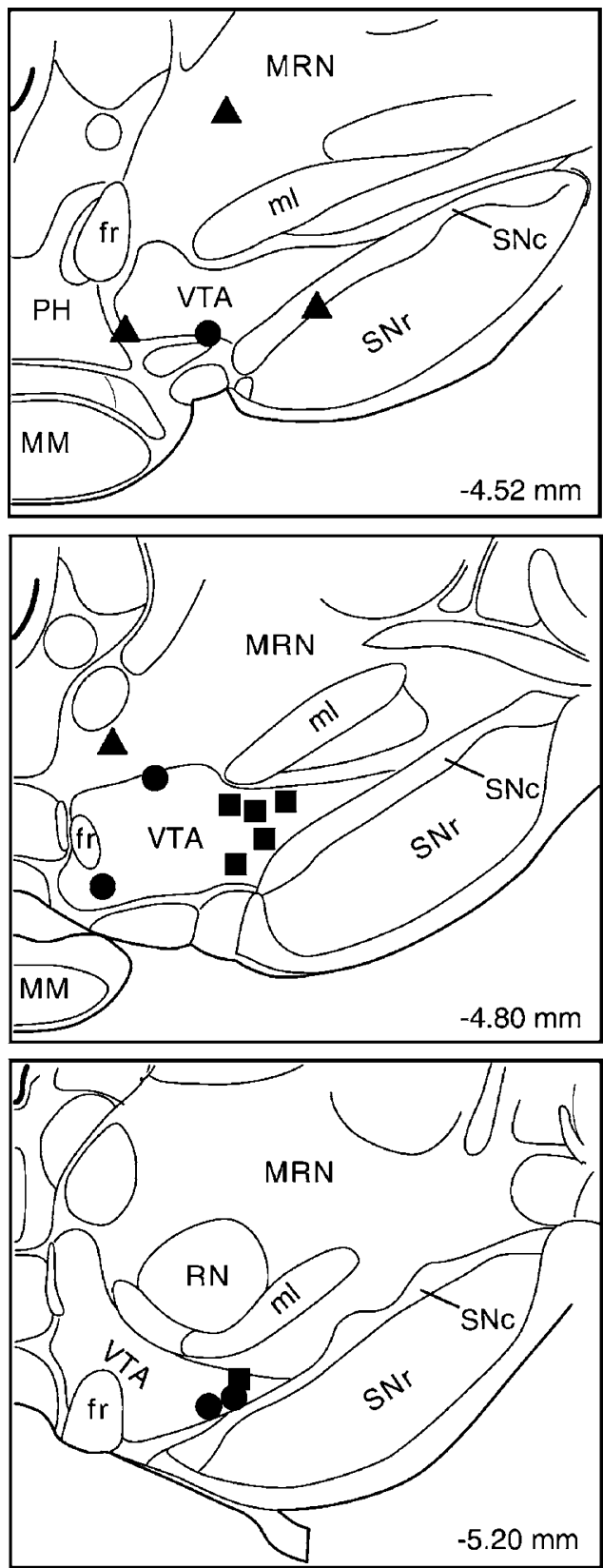

Figure 6 Diagram depicting infusion needle placements within VTA. The placements of needles in animals included in the PFC DA analyses are indicated by squares $(1.0 \mathrm{nmol}$ dose $)$ and circles ( $0.1 \mathrm{nmol}$ dose). Triangles indicate infusions of $1.0 \mathrm{nmol}$ HCRT-I located outside the main body of VTA that did not alter PFC DA levels (modified from Swanson, 1992).

(Figure 6). The mean $( \pm$ SEM) post-infusion PFC DA levels in terms of percentage baseline for the four ineffective placements were $93 \pm 11 \%$ in Sample 1; $103 \pm 16 \%$ in Sample 2; $114 \pm 9 \%$ in Sample 3; and $104 \pm 13 \%$ in Sample 4 .

Similar to that observed with ICV infusions, intra-VTA infusion of the highest dose of HCRT-1 $(1.0 \mathrm{nmol}, n=5)$ had no significant effect on Acc DA levels (time $\mathrm{F}_{9,36}=0.65$, $P=0.75$; Figure $7 \mathrm{~b}$ ). In all of these cases, the placement of the infusion needles within the VTA was comparable to needle placements that resulted in an increase in PFC DA levels. 

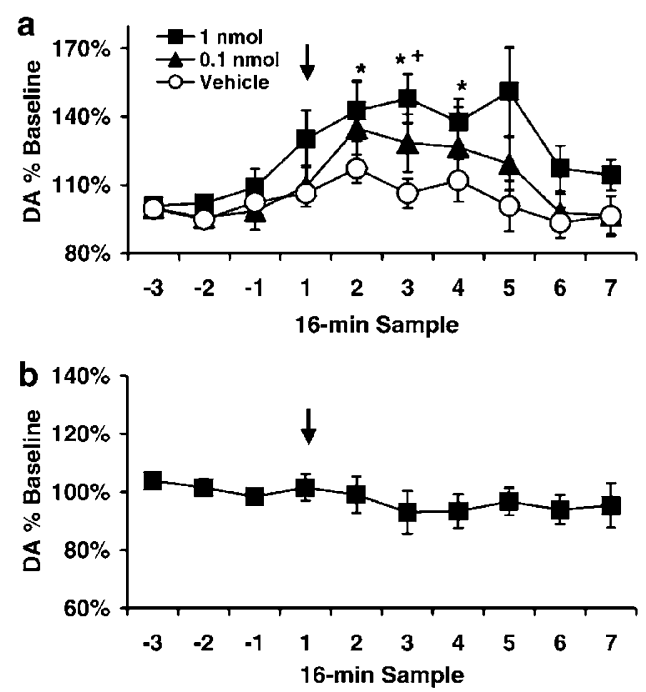

Figure 7 Effects of intra-VTA-administered vehicle, $0.1 \mathrm{nmol}$ and $1.0 \mathrm{nmol}$ HCRT-I on PFC DA levels, and effects of $1.0 \mathrm{nmol}$ HCRT-I on Acc DA levels. DA levels are displayed as a percentage of baseline (mean \pm SEM) for 16-min samples before (negative numbers) and following infusion (positive numbers). The start of the intra-VTA infusion was aligned with the beginning of post-infusion Sample I (arrow). Panel a depicts PFC DA levels. HCRT-I increased DA levels within PFC, with maximum concentrations observed during post-infusion Samples 2-5. Panel b depicts Acc DA levels. HCRT-I had no significant effect on Acc DA levels. ${ }^{+} P<0.05$ compared to vehicle; $* P<0.05$ compared to sample immediately preceding infusion (Sample -1 ).

Effects of intra-VTA HCRT-1 on sleep-wake state and behavior. The degree to which unilateral intra-VTA infusion of HCRT-1 affected the sleep-wake state as well as select behaviors was also assessed. One animal was excluded from these analyses due to inadequate EEG/EMG recordings. HCRT-1 infused directly into VTA significantly increased the time spent awake, as determined from combined EEG/EMG measures (treatment $\mathrm{F}_{2,13}=15.03$, $P<0.001 ;$ time $\mathrm{F}_{9,117}=3.08, \quad P<0.01 ;$ treatment $\times$ time $\left.\mathrm{F}_{18,117}=1.65, \quad P=0.06\right)$. The highest dose of HCRT-1 $(1.0 \mathrm{nmol}, n=6)$ significantly increased the time spent awake for approximately $60 \mathrm{~min}$, with near maximal waking during samples 2-3 (Figure 8a). Neither low-dose HCRT-1 $(0.1 \mathrm{nmol}, n=4)$ nor vehicle $(n=6)$ infusion significantly altered the time spent awake.

Intra-VTA HCRT-1 infusion ( $1.0 \mathrm{nmol}, n=6 ; 0.1 \mathrm{nmol}$, $n=5$; vehicle, $n=6$ ) did not significantly alter locomotor activity as measured by quadrant entries (treatment $\mathrm{F}_{2,14}=3.23, \quad P=0.07$; time $\mathrm{F}_{3,42}=1.61, \quad P=0.20$; treatment $\times$ time $\mathrm{F}_{6,42}=0.85, P=0.54$; Table 1 ) or rears (treatment $\mathrm{F}_{2,14}=2.23, P=0.14 ;$ time $\mathrm{F}_{3,42}=1.95, \quad P=0.14$ treatment $\times$ time $\mathrm{F}_{6,42}=0.82, P=0.56$; Table 1 ). Nonetheless, planned comparisons within the low-dose group revealed a significant increase in rears during the first post-infusion sample relative to baseline, similar to that seen in the ICV study $\left(t_{4}=3.14, P<0.05\right)$. Finally, intraVTA HCRT-1 significantly increased time spent grooming (treatment $\mathrm{F}_{2,14}=4.17, P<0.05$; time $\mathrm{F}_{3,42}=2.56, P=0.07$; treatment $\times$ time $\mathrm{F}_{6,42}=0.32, P=0.92$ ). Significantly more time was spent grooming in the high dose than the vehicle group in the third post-infusion epoch (Table 1). Interest-
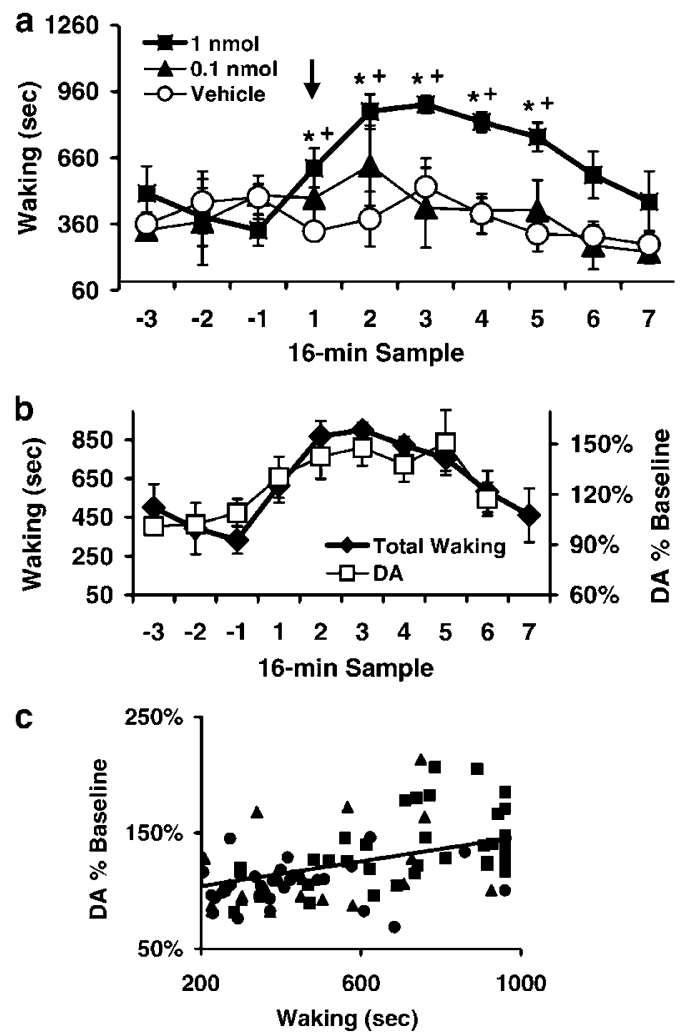

Figure 8 Effects of intra-VTA-administered vehicle, $0.1 \mathrm{nmol}$ and I.0 nmol HCRT-I on time spent awake and relationship between intraVTA HCRT-I-induced increases in PFC DA and waking. (a) Time spent awake based on EEG/EMG measures across 16-min periods. HCRT-I elicited dose-dependent increases in time spent awake. The high dose of HCRT-I induced near-maximal waking for several epochs, followed by a gradual return to baseline. (b) Displayed are mean ( \pm SEM) DA levels (percent baseline) and time spent awake (sec). It is evident that there is a close temporal relationship between HCRT-I-induced $(1.0 \mathrm{nmol}$ intraVTA) increases in DA levels and waking. (c) Scatterplot showing the best fit line between waking and DA levels over all seven post-infusion samples. Different shapes represent treatment groups: squares $(1.0 \mathrm{nmol})$; triangles (0.I nmol); circles (vehicle). Regression analyses indicated a strong positive correlation between PFC DA levels and time spent awake after intra-VTA infusion of HCRT-I (best-fit regression $r=0.56, r^{2}=0.31$ ). ${ }^{+} P<0.05$ compared to vehicle; $* P<0.05$ compared to epoch immediately preceding infusion (Epoch - I)

ingly, the increase in grooming observed following intraVTA infusion was significantly greater than that observed following ICV infusion of high-dose HCRT-1 (treatment $\mathrm{F}_{1,9}=8.11, \quad P<0.05 ;$ time $\mathrm{F}_{3,27}=2.90, \quad P=0.05$; treatment $\times$ time $\mathrm{F}_{3,27}=0.44, P=0.73$ ), particularly during the second post-infusion epoch $\left(\mathrm{F}_{1,9}=7.67, P<0.05\right.$; data not shown).

Relationship between intra-VTA HCRT-1-induced alterations in behavior and PFC DA levels. Correlation analyses were conducted to better assess the degree to which the intra-VTA HCRT-1-induced increase in PFC DA efflux might contribute to HCRT-1-induced alterations in behavioral state and specific behaviors. As shown in Figure 8b, there was a close temporal association between HCRT-1induced increases in PFC DA levels and time spent awake. Additionally, best-fit regression analyses on data pooled across all groups and post-infusion epochs (seven 16-min 

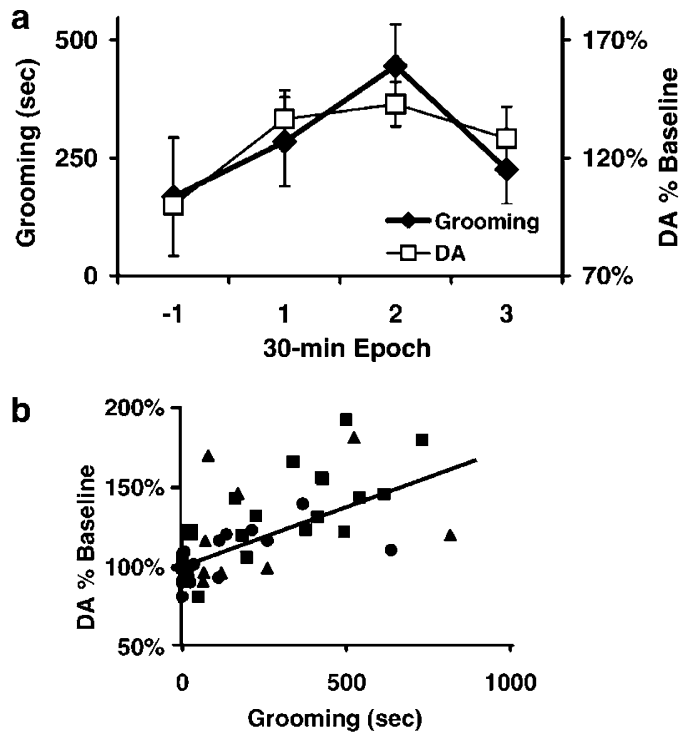

Figure 9 Relationship between intra-VTA HCRT-I-induced increases in PFC DA and grooming. (a) Displayed are mean ( \pm SEM) DA levels (percent baseline) and time spent grooming (sec). It is evident that there is a relatively close temporal relationship between HCRT-I-induced ( $1.0 \mathrm{nmol}$ intra-VTA) increases in DA levels and grooming. (b) Scatterplot showing the best-fit line between grooming and DA levels across the first 90-min post-infusion. Different shapes represent treatment groups: squares $(1.0 \mathrm{nmol})$; triangles $(0.1 \mathrm{nmol})$; circles (vehicle). Regression analyses indicated a strong positive correlation between PFC DA levels and time spent grooming after intra-VTA infusion of HCRT-I (best-fit regression $\left.r=0.65, r^{2}=0.43\right)$.

samples for waking; three 30-min samples for behavior) indicated a strong positive correlation between postinfusion PFC DA levels and time spent awake $(r=0.56$, $r^{2}=0.31, P<0.001$; Figure $8 \mathrm{c}$ ). The time course of the DA response also largely corresponds with the time course of HCRT-1-induced grooming (Figure 9a). Furthermore, there was a strong positive correlation between post-infusion DA levels in PFC and time spent grooming $\left(r=0.65, r^{2}=0.43\right.$, $P<0.001$; Figure 9b). Positive correlations were also observed when data from each group were analyzed separately. Less robust correlations were observed with quadrant entries $\left(r=0.37, r^{2}=0.14, P<0.01\right)$ and rears $\left(r=0.38, r^{2}=0.14, P<0.01\right)$.

\section{DISCUSSION}

Available evidence indicates that the HCRTs act within multiple systems associated with the modulation of behavioral state. These include basal forebrain (España et al, 2001; Thakkar et al, 2001) and brainstem structures such as the locus coeruleus (Hagan et al, 1999; Horvath et al, 1999; Bourgin et al, 2000), the dorsal raphe (Liu et al, 2002; Kohlmeier et al, 2004), the lateral dorsal tegmental nucleus (Burlet et al, 2002; Kohlmeier et al, 2004) and the tuberomammillary nucleus (Eriksson et al, 2001). DA systems have also been implicated in the modulation of behavioral state and state-dependent processes, particularly under high arousal appetitive and aversive conditions (Trulson, 1985; Smith et al, 1992; Arnsten et al, 1994; Isaac and Berridge, 2003). Thus, it is of interest that VTA and substantia nigra neurons express HCRT receptor mRNA (Marcus et al, 2001) and that HCRT activates VTA (though not substantia nigra) DA neurons in vitro (Uramura et al, 2001; Korotkova et al, 2002, 2003).

To examine initially the modulatory actions of HCRT on DA neurotransmission in vivo, the current studies utilized microdialysis measures of DA release within the PFC and Acc in the unanesthetized rat. These studies demonstrate a robust and dose-dependent increase in DA efflux within the PFC, but not within Acc, following ICV-administered HCRT-1. HCRT fibers are located in close proximity to DA cell bodies in the VTA, a major source of PFC- and Accprojecting DA neurons (Fadel and Deutch, 2002; Baldo et al, 2003). To test the hypothesis that HCRT acts directly within the VTA to increase DA neurotransmission, we examined the effects of intra-VTA infusion of HCRT-1 on DA efflux within the PFC and Acc. Intra-VTA administration of HCRT-1 increased DA levels within the PFC and not Acc, a pattern similar to that observed with ICV administration.

\section{Methodological Considerations}

Microdialysis probes were lowered slowly over a 5-10-min period 1 or 2 days prior to testing. This procedure was based on previous observations indicating that slow implantation results in substantially higher extracellular levels of norepinephrine and DA within the PFC relative to rapid insertion via an indwelling cannula. The magnitude of stressor-induced activation of DA efflux within the PFC and Acc estimated with these procedures is comparable to that observed with both postmortem measures and dialysis probe implantation 7 days following surgical implantation of a guide cannula (Abercrombie et al, 1989; Berridge et al, 1999a; Feenstra et al, 2000). Moreover, the magnitude of HCRT-induced waking observed following only 1-2 days recovery from surgery in the current studies was comparable to previous observations in animals given a recovery period of at least 7 days (España et al, 2001). Therefore, the stress of surgery 1-2 days prior to testing does not appear to compromise the reactivity of DA terminals to arousalincreasing environments or the wake-promoting actions of HCRT.

Although we did not observe an increase in Acc DA levels after either ICV or intra-VTA HCRT infusion, it has been well established by our laboratory and others that such an increase can occur under similar experimental conditions (Westerink et al, 1996; Ikemoto et al, 1997; Berridge et al, 1999a, 2003).

\section{Circuitry Underlying Selective Increase in DA Efflux by HCRT}

The current observations demonstrate the selective increase by HCRT-1 of DA efflux within the PFC relative to Acc. These two regions are of particular interest because previous work demonstrates that DA terminals within the PFC and Acc display greater responsivity to salient stimuli relative to other cortical (eg cingulate cortex) and subcortical (eg striatum, hypothalamus) DA terminal fields (Dunn, 1988; Roth et al, 1988; Feenstra et al, 2000). Thus, given the apparent lack of sensitivity of Acc DA terminals to HCRT-1, it seems unlikely that HCRT-1 activates DA 
terminals within these other areas. An exception to the general rule of reduced responsivity of DA terminals outside of PFC and Acc is the central nucleus of the amygdala (Kilts and Anderson, 1987; Inglis and Moghaddam, 1999). The extent to which HCRT influences rates of DA neurotransmission within the amygdala remains to be determined.

The selective increase in PFC DA efflux following intraVTA infusion of HCRT-1 is somewhat surprising, given that VTA (and substantia nigra) DA neurons project to both PFC and Acc. This could result from a number of mechanisms. First, differential actions of autoreceptors (Chiodo and Bunney, 1983) and/or DA transporters (Sesack et al, 1998) across terminal fields may contribute to enhanced DA efflux within the PFC. Additionally, anatomical and physiological evidence indicates that PFC-projecting DA neurons differ from Acc-projecting DA neurons in receptor expression and distribution within the VTA (Swanson, 1982; Deutch et al, 1991; Roeper et al, 2003; Garzon and Pickel, 2004; Margolis et al, 2004). Thus, it is possible that this subpopulation of DA neurons display a greater sensitivity to salient environmental stimuli and/or HCRT-1 than other, non-PFCprojecting, DA neurons. Finally, ICV infusion of HCRT may activate LH HCRT neurons via neighboring glutamatergic neurons (Li et al, 2002), which project both to VTA and PFC, but only sparsely to Acc (Fadel and Deutch, 2002).

In the case of intra-VTA infusion of HCRT-1, comparable or larger doses were required to elicit an increase in PFC DA efflux similar to that observed with ICV infusion. This could reflect a number of possible mechanisms. First, it may be related to the relatively low density of HCRT synapses onto DA neurons within the VTA (Balcita-Pedicino and Sesack, 2003). Second, ICV infusions will impact multiple sources of PFC-projecting DA efferents not targeted by unilateral intra-VTA infusions (eg, A8, A9, contralateral VTA; Swanson, 1982; Deutch et al, 1991). However, it is important to note that, consistent with the results of our limited mapping study, HCRT-1 does not excite substantia nigra DA neurons in vitro (Korotkova et al, 2002). Third, PFCprojecting DA neurons are located primarily within the caudal portion of the VTA (Swanson, 1982; Deutch et al, 1991; Roeper et al, 2003; Garzon and Pickel, 2004). Given that this neuronal population was not specifically targeted in this study and given relatively small infusion volumes, higher doses may have been required to permit consistent diffusion of HCRT-1 to this region of the VTA. Additionally, ICV-administered HCRT-1 may also act via a multisynaptic pathway and/or directly within the PFC to modulate rates of DA neurotransmission. Finally, ICV HCRT-induced activation of the locus coeruleus (Hagan et al, 1999) may result in efflux of DA from noradrenergic terminals within the PFC (Devoto et al, 2003). Regardless of whether the VTA is the sole site of action, the current observations nonetheless demonstrate that HCRT acts directly within the VTA to increase rates of DA release within the PFC. Further studies are needed to fully delineate the circuitry underlying HCRTdependent activation of PFC DA neurotransmission.

\section{HCRT-DA Interactions: Implications for Behavioral State}

Intra-VTA infusion of HCRT-1 increased the time spent awake, providing the first demonstration that HCRT-1 acts within the VTA to modulate behavioral state. It is not clear from these observations alone whether this involves HCRTinduced activation of DA neurotransmission. However, there was a strong positive relationship between HCRT-1induced increases in waking and rates of PFC DA release following both ICV and intra-VTA infusions. Combined, these observations suggest that the wake-promoting actions of HCRT likely involve the activation of DA neurons located within the VTA. Future studies will need to determine the degree to which HCRT acts on DA neurons or other neurons within the VTA to promote waking.

Importantly, HCRT-induced increases in PFC DA efflux do not appear to result simply from the wake-promoting actions of this peptide. The waking state is associated with an approximately $25 \%$ increase in PFC DA dialysate levels over sleeping baseline (Berridge and Stalnaker, 2002), much less than the observed PFC DA response to ICV or intraVTA HCRT infusion. The observed HCRT-induced increases in PFC DA efflux are comparable to those observed under high-arousal conditions (see below).

In the current studies, the dose of intra-VTA HCRT-1 required to promote waking was somewhat higher than that observed for basal forebrain infusions (España et al, 2001). However, it is important to note that the current studies utilized unilateral infusions, whereas these previous studies infused HCRT-1 bilaterally. Similarly, when infused into the basal forebrain, amphetamine displays substantially greater potency when infused bilaterally (Berridge et al, 1999b). Thus, it is predicted that the dose-response curve for the wake-promoting actions of intra-VTA HCRT-1 would be shifted to the left with bilateral infusions.

\section{HCRT-DA Interactions in Aversive and Appetitive Conditions}

Accumulating evidence suggests a role for HCRT neurotransmission in high-arousal processes associated with stress and/or appetitive states. For example, the feedingpromoting actions of HCRT may reflect a potentially broader role of HCRT in appetitive processes (Willie et al, 2001). Additionally, ICV HCRT-1 elicits a variety of stresslike physiological and behavioral responses, including activation of the hypothalamo-pituitary-adrenal axis (Jaszberenyi et al, 2000; Kuru et al, 2000), increased $c$-fos expression (España et al, 2003), locomotor activation, grooming, and the chewing of inedible material (Nakamura et al, 2000; España et al, 2001). Intra-VTA infusions of HCRT-1 also provoked certain stress-like behaviors, including grooming. The increase in time spent grooming was closely associated with HCRT-induced increases in PFC DA efflux. Moreover, ICV HCRT-induced grooming is attenuated by pretreatment with DA receptor antagonists (Nakamura et al, 2000). Combined, these observations suggest that HCRT participates in regulating behavior in stress, including the induction of a high-arousal state, via actions upon VTA DA neurons.

The current studies demonstrate that HCRT elicits an activation of PFC DA systems comparable to that observed in both aversive and appetitive high-arousal states (Abercrombie et al, 1989; Cenci et al, 1992; Gresch et al, 1994; Di Chiara et al, 1999; Feenstra et al, 2000), and that this involves, at least in part, actions within the VTA. These 
observations suggest that HCRT contributes to the relatively selective activation of PFC DA projections under appetitive and/or aversive conditions. It should be noted that, often, stress-related increases in PFC DA release are accompanied by smaller, though substantial, increases in Acc DA release (Abercrombie et al, 1989; Cenci et al, 1992; Gresch et al, 1994; Di Chiara et al, 1999; Feenstra et al, 2000). Thus, the effect of HCRT-1 on DA neurotransmission is not entirely similar to that observed in stress. Nonetheless, the selective activation of DA projections to PFC relative to Acc in stress has been consistently observed (Roth et al, 1988). As such, the degree to which HCRT-1-induced activation of PFC DA projections mimics that observed in stress and/or appetitive states remains unclear.

\section{Potential Role of HCRT in the Modulation of PFC-Dependent Cognitive and Affective Processes}

PFC DA neurotransmission plays a pivotal role in a variety of higher-order cognitive and affective processes. These include learning under both appetitive and aversive conditions (Sokolowski and Salamone, 1994; Wilkinson et al, 1998; Bassareo and Di Chiara, 1997; Baldwin et al, 2002), working memory (Arnsten et al, 1994; Williams and Goldman-Rakic, 1995; Murphy et al, 1996; Phillips et al, 2004), and attention (Robbins, 2000). Additional evidence indicates a prominent role of the PFC and PFC DA in a variety of affective processes (for example, see Jentsch $e t$ al, 2000; Davidson, 2003). Given this, it is of interest that HCRT-1 produces a robust and apparently selective increase in PFC DA efflux. These observations suggest that HCRT likely impacts PFC-dependent cognitive and affective processes via alterations in rates of DA neurotransmission within the PFC. Clearly, the degree to which HCRT modulates PFC-dependent affect and cognition, and may contribute to affective and/or cognitive dysfunction associated with a variety of psychiatric/behavioral disorders, is an important question for future studies.

\section{Conclusions}

The present studies demonstrated the selective increase in PFC DA efflux by HCRT-1 relative to Acc. This activation involved, at least in part, direct actions of HCRT within the VTA. Moreover, intra-VTA infusions of HCRT-1 produced an increase in time spent awake that was closely associated with HCRT-1-induced increases in PFC DA efflux. Combined, these observations suggest a prominent role of the VTA and DA neurotransmission in the modulatory actions of HCRT on behavioral state and PFC-dependent affective and cognitive processes.

\section{ACKNOWLEDGEMENTS}

This work was supported by the University of Wisconsin Graduate School, PHS grants MH62359, DA10681, DA00389 (CWB), and an NSF Predoctoral award (NMV). We gratefully acknowledge Christina Hamilton, MS, Heather Dodson and Thomas Stalnaker, $\mathrm{PhD}$, for their assistance in this project.

\section{REFERENCES}

Abercrombie ED, Keefe KA, DiFrischia DS, Zigmond MJ (1989). Differential effect of stress on in vivo dopamine release in striatum, nucleus accumbens, and medial frontal cortex. J Neurochem 52: 1655-1658.

Arnsten AF, Cai JX, Murphy BL, Goldman-Rakic PS (1994). Dopamine D1 receptor mechanisms in the cognitive performance of young adult and aged monkeys. Psychopharmacology (Berl) 116: 143-151.

Balcita-Pedicino JJ, Sesack SR (2003). The orexin projection to the ventral tegmental area in the rat: synaptic interactions with dopamine and GABA neurons. Society for Neuroscience Abstracts Program No. 508.5.

Baldo BA, Daniel RA, Berridge CW, Kelley AE (2003). Overlapping distributions of orexin/hypocretin- and dopamine-betahydroxylase immunoreactive fibers in rat brain regions mediating arousal, motivation, and stress. J Comp Neurol 464: 220-237.

Baldwin AE, Sadeghian K, Kelley AE (2002). Appetitive instrumental learning requires coincident activation of NMDA and dopamine D1 receptors within the medial prefrontal cortex. J Neurosci 22: 1063-1071.

Bassareo V, Di Chiara G (1997). Differential influence of associative and nonassociative learning mechanisms on the responsiveness of prefrontal and accumbal dopamine transmission to food stimuli in rats fed ad libitum. J Neurosci 17: 851-861.

Berridge CW, Foote SL (1996). Enhancement of behavioral and electroencephalographic indices of waking following stimulation of noradrenergic beta-receptors within the medial septal region of the basal forebrain. J Neurosci 16: 6999-7009.

Berridge CW, Mitton E, Clark W, Roth RH (1999a). Engagement in a non-escape (displacement) behavior elicits a selective and lateralized suppression of frontal cortical dopaminergic utilization in stress. Synapse 32: 187-197.

Berridge CW, O’Neil J, Wifler K (1999b). Amphetamine acts within the medial basal forebrain to initiate and maintain alert waking. Neuroscience 93: 885-896.

Berridge CW, Schmeichel B, Hamilton CM, Devilbiss DM (2003). Differential impact of low-dose methylphenidate on dopamine efflux within prefrontal cortex and nucleus accumbens. Society for Neuroscience Abstracts Program No. 324.2.

Berridge CW, Stalnaker TA (2002). Relationship between low-dose amphetamine-induced arousal and extracellular norepinephrine and dopamine levels within prefrontal cortex. Synapse 46: 140-149.

Bourgin P, Huitron-Resendiz S, Spier AD, Fabre V, Morte B, Criado JR. et al (2000). Hypocretin-1 modulates rapid eye movement sleep through activation of locus coeruleus neurons. J Neurosci 20: 7760-7765.

Burlet S, Tyler CJ, Leonard CS (2002). Direct and indirect excitation of laterodorsal tegmental neurons by hypocretin/ orexin peptides: implications for wakefulness and narcolepsy. J Neurosci 22: 2862-2872.

Cenci MA, Kalen P, Mandel RJ, Bjorklund A (1992). Regional differences in the regulation of dopamine and noradrenaline release in medial frontal cortex, nucleus accumbens and caudate-putamen: a microdialysis study in the rat. Brain Res 581: $217-228$.

Chiodo LA, Bunney BS (1983). Typical and atypical neuroleptics: differential effects of chronic administration on the activity of A9 and A10 midbrain dopaminergic neurons. J Neurosci 3: $1607-1619$.

Davidson RJ (2003). Affective neuroscience and psychophysiology: toward a synthesis. Psychophysiology 40: 655-665.

de Lecea L, Kilduff TS, Peyron C, Gao X, Foye PE, Danielson PE et al (1998). The hypocretins: hypothalamus-specific peptides 
with neuroexcitatory activity. Proc Natl Acad Sci USA 95: 322-327.

Deutch AY, Lee MC, Gillham MH, Cameron DA, Goldstein M, Iadarola MJ (1991). Stress selectively increases fos protein in dopamine neurons innervating the prefrontal cortex. Cereb Cortex 1: 273-292.

Devoto P, Flore G, Longu G, Pira L, Gessa GL (2003). Origin of extracellular dopamine from dopamine and noradrenaline neurons in the medial prefrontal and occipital cortex. Synapse 50: 200-205.

Di Chiara G, Loddo P, Tanda G (1999). Reciprocal changes in prefrontal and limbic dopamine responsiveness to aversive and rewarding stimuli after chronic mild stress: implications for the psychobiology of depression. Biol Psychiatry 46: 1624-1633.

Dunn AJ (1988). Stress-related activation of cerebral dopaminergic systems. Ann NY Acad Sci 537: 188-205.

Eriksson KS, Sergeeva O, Brown RE, Haas HL (2001). Orexin/ hypocretin excites the histaminergic neurons of the tuberomammillary nucleus. J Neurosci 21: 9273-9279.

España RA, Baldo BA, Kelley AE, Berridge CW (2001). Wakepromoting and sleep-suppressing actions of hypocretin (orexin): basal forebrain sites of action. Neuroscience 106: 699-715.

España RA, Valentino RJ, Berridge CW (2003). Fos immunoreactivity in hypocretin-synthesizing and hypocretin-1 receptor-expressing neurons: effects of diurnal and nocturnal spontaneous waking, stress and hypocretin-1 administration. Neuroscience 121: 201-217.

Fadel J, Deutch AY (2002). Anatomical substrates of orexindopamine interactions: lateral hypothalamic projections to the ventral tegmental area. Neuroscience 111: 379-387.

Feenstra MG, Botterblom MH, Mastenbroek S (2000). Dopamine and noradrenaline efflux in the prefrontal cortex in the light and dark period: effects of novelty and handling and comparison to the nucleus accumbens. Neuroscience 100: 741-748.

Garzon M, Pickel VM (2004). Ultrastructural localization of Leu5enkephalin immunoreactivity in mesocortical neurons and their input terminals in rat ventral tegmental area. Synapse 52: 38-52.

Gresch PJ, Sved AF, Zigmond MJ, Finlay JM (1994). Stress-induced sensitization of dopamine and norepinephrine efflux in medial prefrontal cortex of the rat. J Neurochem 63: 575-583.

Hagan JJ, Leslie RA, Patel S, Evans ML, Wattam TA, Holmes S et al (1999). Orexin A activates locus coeruleus cell firing and increases arousal in the rat. Proc Natl Acad Sci USA 96: 1091110916.

Horvath TL, Peyron C, Diano S, Ivanov A, Aston-Jones G, Kilduff TS et al (1999). Hypocretin (orexin) activation and synaptic innervation of the locus coeruleus noradrenergic system. J Comp Neurol 415: 145-159.

Hungs M, Mignot E (2001). Hypocretin/orexin, sleep and narcolepsy. BioEssays 23: 397-408.

Ida T, Nakahara K, Murakami T, Hanada R, Nakazato M, Murakami N (2000). Possible involvement of orexin in the stress reaction in rats. Biochem Biophys Res Commun 270: 318-323.

Ikemoto S, Kohl RR, McBride WJ (1997). GABA(A) receptor blockade in the anterior ventral tegmental area increases extracellular levels of dopamine in the nucleus accumbens of rats. J Neurochem 69: 137-143.

Ikemoto S, Panksepp J (1999). The role of nucleus accumbens dopamine in motivated behavior: a unifying interpretation with special reference to reward-seeking. Brain Res Brain Res Rev 31: 6-41.

Inglis FM, Moghaddam B (1999). Dopaminergic innervation of the amygdala is highly responsive to stress. J Neurochem 72: 1088-1094.

Isaac SO, Berridge CW (2003). Wake-promoting actions of dopamine D1 and D2 receptor stimulation. J Pharmacol Exp Ther 307: 386-394.
Jaszberenyi M, Bujdoso E, Pataki I, Telegdy G (2000). Effects of orexins on the hypothalamic-pituitary-adrenal system. J Neuroendocrinol 12: 1174-1178.

Jentsch JD, Roth RH, Taylor JR (2000). Role for dopamine in the behavioral functions of the prefrontal corticostriatal system: implications for mental disorders and psychotropic drug action. Prog Brain Res 126: 433-453.

Kilts CD, Anderson CM (1987). Mesoamygdaloid dopamine neurons: differential rates of dopamine turnover in discrete amygdaloid nuclei of the rat brain. Brain Res 416: 402-408.

Kohlmeier KA, Inoue T, Leonard CS (2004). Hypocretin/orexin peptide signaling in the ascending arousal system: elevation of intracellular calcium in the mouse dorsal raphe and laterodorsal tegmentum. J Neurophysiol 92: 221-235.

Korotkova TM, Eriksson KS, Haas HL, Brown RE (2002). Selective excitation of GABAergic neurons in the substantia nigra of the rat by orexin/hypocretin in vitro. Regul Pept 104: 83-89.

Korotkova TM, Sergeeva OA, Eriksson KS, Haas HL, Brown RE (2003). Excitation of ventral tegmental area dopaminergic and nondopaminergic neurons by orexins/hypocretins. J Neurosci 23: 7-11.

Kuru M, Ueta Y, Serino R, Nakazato M, Yamamoto Y, Shibuya I et al (2000). Centrally administered orexin/hypocretin activates HPA axis in rats. Neuroreport 11: 1977-1980.

Li Y, Gao XB, Sakurai T, van den Pol AN (2002). Hypocretin/orexin excites hypocretin neurons via a local glutamate neuron-a potential mechanism for orchestrating the hypothalamic arousal system. Neuron 36: 1169-1181.

Liu RJ, van den Pol AN, Aghajanian GK (2002). Hypocretins (orexins) regulate serotonin neurons in the dorsal raphe nucleus by excitatory direct and inhibitory indirect actions. $J$ Neurosci 22: 9453-9464.

Marcus JN, Aschkenasi CJ, Lee CE, Chemelli RM, Saper CB, Yanagisawa $M$ et al (2001). Differential expression of orexin receptors 1 and 2 in the rat brain. J Comp Neurol 435: 6-25.

Margolis EB, Lock H, Hjelmstad GO, Fields HL (2004). Direct kappa opioid action on ventral tegmental area dopaminergic neurons is dependent on projection target. Society for Neuroscience Abstracts Program No. 46.9.

Murphy BL, Arnsten AF, Jentsch JD, Roth RH (1996). Dopamine and spatial working memory in rats and monkeys: pharmacological reversal of stress-induced impairment. J Neurosci 16: 7768-7775.

Nakamura T, Uramura K, Nambu T, Yada T, Goto K, Yanagisawa $\mathrm{M}$ et al (2000). Orexin-induced hyperlocomotion and stereotypy are mediated by the dopaminergic system. Brain Res 873: 181-187.

National Institutes of Health (US) Institute of Laboratory Animal Resources (1996). Guide for the Care and Use of Laboratory Animals. National Academy Press: Washington, DC.

Peyron C, Tighe DK, van den Pol AN, de Lecea L, Heller HC, Sutcliffe JG et al (1998). Neurons containing hypocretin (orexin) project to multiple neuronal systems. J Neurosci 18: 9996-10015.

Phillips AG, Ahn S, Floresco SB (2004). Magnitude of dopamine release in medial prefrontal cortex predicts accuracy of memory on a delayed response task. J Neurosci 24: 547-553.

Piper DC, Upton N, Smith MI, Hunter AJ (2000). The novel brain neuropeptide, orexin-A, modulates the sleep-wake cycle of rats. Eur J Neurosci 12: 726-730.

Robbins TW (2000). Chemical neuromodulation of frontalexecutive functions in humans and other animals. Exp Brain Res 133: 130-138.

Roeper J, Liss B, Jones IW (2003). Mapping and functional properties of mesoprefrontal dopaminergic neurons in adult mice. Society for Neuroscience Abstracts Program No. 600.8.

Roth RH, Tam SY, Ida Y, Yang JX, Deutch AY (1988). Stress and the mesocorticolimbic dopamine systems. Ann NY Acad Sci 537: 138-147. 
Sakurai T, Amemiya A, Ishii M, Matsuzaki I, Chemelli RM, Tanaka $\mathrm{H}$ et al (1998). Orexins and orexin receptors: a family of hypothalamic neuropeptides and $\mathrm{G}$ protein-coupled receptors that regulate feeding behavior. Cell 92: 573-585.

Samson WK, Taylor MM, Follwell M, Ferguson AV (2002). Orexin actions in hypothalamic paraventricular nucleus: physiological consequences and cellular correlates. Regul Pept 104: 97-103.

Scammell TE (2001). Wakefulness: an eye-opening perspective on orexin neurons. Curr Biol 11: R769-R771.

Sesack SR, Hawrylak VA, Matus C, Guido MA, Levey AI (1998). Dopamine axon varicosities in the prelimbic division of the rat prefrontal cortex exhibit sparse immunoreactivity for the dopamine transporter. J Neurosci 18: 2697-2708.

Smith AD, Olson RJ, Justice Jr JB (1992). Quantitative microdialysis of dopamine in the striatum: effect of circadian variation. J Neurosci Methods 44: 33-41.

Smith-Roe SL, Kelley AE (2000). Coincident activation of NMDA and dopamine D1 receptors within the nucleus accumbens core is required for appetitive instrumental learning. J Neurosci 20: 7737-7742.

Sokolowski JD, Salamone JD (1994). Effects of dopamine depletions in the medial prefrontal cortex on DRL performance and motor activity in the rat. Brain Res 642: 20-28.

Swanson LW (1982). The projections of the ventral tegmental area and adjacent regions: a combined fluorescent retrograde tracer and immunofluorescence study in the rat. Brain Res Bull 9: 321-353.

Swanson LW (1992). Brain Maps: Structure of the Rat Brain. Elsevier: Amsterdam.
Thakkar MM, Ramesh V, Strecker RE, McCarley RW (2001). Microdialysis perfusion of orexin-A in the basal forebrain increases wakefulness in freely behaving rats. Arch Ital Biol 139: 313-328.

Thierry AM, Tassin JP, Blanc G, Glowinski J (1976). Selective activation of mesocortical DA system by stress. Nature 263: 242-244.

Trulson ME (1985). Simultaneous recording of substantia nigra neurons and voltammetric release of dopamine in the caudate of behaving cats. Brain Res Bull 15: 221-223.

Uramura K, Funahashi H, Muroya S, Shioda S, Takigawa M, Yada $\mathrm{T}$ (2001). Orexin-a activates phospholipase C- and protein kinase $\mathrm{C}$-mediated $\mathrm{Ca}^{2+}$ signaling in dopamine neurons of the ventral tegmental area. Neuroreport 12: 1885-1889.

Westerink BH, Kwint HF, deVries JB (1996). The pharmacology of mesolimbic dopamine neurons: a dual-probe microdialysis study in the ventral tegmental area and nucleus accumbens of the rat brain. J Neurosci 16: 2605-2611.

Wilkinson LS, Humby T, Killcross AS, Torres EM, Everitt BJ, Robbins TW (1998). Dissociations in dopamine release in medial prefrontal cortex and ventral striatum during the acquisition and extinction of classical aversive conditioning in the rat. Eur $J$ Neurosci 10: 1019-1026.

Williams GV, Goldman-Rakic PS (1995). Modulation of memory fields by dopamine D1 receptors in prefrontal cortex. Nature 376: $572-575$.

Willie JT, Chemelli RM, Sinton CM, Yanagisawa M (2001). To eat or to sleep? Orexin in the regulation of feeding and wakefulness. Annu Rev Neurosci 24: 429-458. 